\title{
First principles study of electronic, elastic, optical and magnetic properties of Rh2MnX (X=Ti, Hf, Sc, Zr, Zn) Heusler alloys
}

\author{
Emre GÜLER ${ }^{1}$, Melek GÜLER ${ }^{1}$, Şule Uğur ${ }^{2}$, and Gökay Uğur ${ }^{2}$ \\ ${ }^{1}$ Ankara Haci Bayram Veli University \\ ${ }^{2}$ Faculty of Science
}

November 23, 2020

\begin{abstract}
We report the electronic, elastic, mechanical, optical and magnetic properties of Rh2MnX (X=Ti, Hf, Sc, Zr, Zn) Heusler alloys performed within density functional theory (DFT). The generalized gradient approximation (GGA) was used for calculations in the context of the Perdew-Burke-Ernzerhof (PBE) exchange-correlation energy treatment. The computed elastic constants and elastic moduli show that all investigated alloys are mechanically stable and ductile. It has been found that the magnitudes of the theoretical Vickers hardness values of these alloys are in the range of $\mathrm{Ti}>\mathrm{Sc}>\mathrm{Zr}>\mathrm{Hf}>\mathrm{Zn}$. Also, a typical metallic behavior is obtained for all alloys after agreement of mechanical, electronic and optical data. On the other side, all alloys show strong ferromagnetic ordering following the magnetic moment (?B) rank of $\mathrm{Ti}>\mathrm{Zr}>\mathrm{Hf}>\mathrm{Sc}>\mathrm{Zn}$. Our calculated ?B data also agree well with the former theoretical results of $\mathrm{Rh} 2 \mathrm{MnX}(\mathrm{X}=\mathrm{Ti}, \mathrm{Hf}, \mathrm{Sc}, \mathrm{Zr}, \mathrm{Zn})$ Heusler alloys.
\end{abstract}

First principles study ofelectronic, elastic, optical and magnetic properties of $\operatorname{Rh}_{\mathbf{2}} \mathrm{MnX}(X=T i$, $H f, S c, Z r, Z n$ ) Heusler alloys

E. Güler ${ }^{*}, M$. Güler ${ }^{1}, S$ S. Uğur ${ }^{2}$ and G. Uğur ${ }^{2}$

${ }^{1}$ Department of Physics, Ankara Hacı Bayram Veli University 06900 Ankara, Turkey

${ }^{2}$ Department of Physics, Faculty of Science, Gazi University 06500 Ankara, Turkey

Abstract

We report the electronic, elastic, mechanical, optical and magnetic properties of $\mathrm{Rh}_{2} \mathrm{MnX}(\mathrm{X}=\mathrm{Ti}, \mathrm{Hf}, \mathrm{Sc}$, $\mathrm{Zr}, \mathrm{Zn}$ ) Heusler alloys performed within density functional theory (DFT). The generalized gradient approximation (GGA) was used for calculations in the context of the Perdew-Burke-Ernzerhof (PBE) exchangecorrelation energy treatment. The computed elastic constants and elastic moduli show that all investigated alloys are mechanically stable and ductile. It has been found that the magnitudes of the theoretical Vickers hardness values of these alloys are in the range of $\mathrm{Ti}>\mathrm{Sc}>\mathrm{Zr}>\mathrm{Hf}>\mathrm{Zn}$. Also, a typical metallic behavior is obtained for all alloys after agreement of mechanical, electronic and optical data. On the other side, all alloys show strong ferromagnetic ordering following the magnetic moment $\left(\mu_{\mathrm{B}}\right)$ rank of $\mathrm{Ti}>\mathrm{Zr}>\mathrm{Hf}>\mathrm{Sc}$ $>\mathrm{Zn}$. Our calculated $\mu_{\mathrm{B}}$ data also agree well with the former theoretical results of $\mathrm{Rh}_{2} \mathrm{MnX}(\mathrm{X}=\mathrm{Ti}, \mathrm{Hf}, \mathrm{Sc}$, $\mathrm{Zr}, \mathrm{Zn}$ ) Heusler alloys.

Keywords : Full Heusler; electronic; elastic; magnetic; optical; DFT.

* Corresponding author

Telephone: +90 (312) 6237394 Fax: +90 (312) 6228573 
E-mail: eguler71@gmail.com

Introduction

After their discovery by F. Heusler [1,2] in 1903, Heusler alloys became an indispensable group of materials for rapidly developing technology with their widespread use [3-10]. For example, they are excellent candidates for spintronics, shape memory alloys, ferroics, magneto-caloric materials, skyrmions, etc. [11]. In general, Heusler alloys classify into four main structural groups as full Heusler alloys, half Heusler alloys, inverse Heusler alloys and quaternary Heusler alloys [11]. From them, two main groups of Heusler alloys exist with

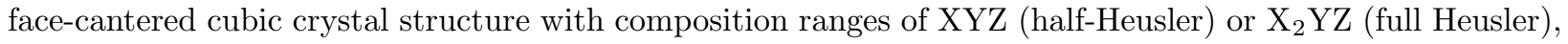
where $\mathrm{X}$ and $\mathrm{Y}$ are transition metals and $\mathrm{Z}$ is a p-block element the periodic table. Besides, inverse Heusler alloys emerge with the formula $\mathrm{X}_{2} \mathrm{YZ}$ where $\mathrm{Y}$ element has a larger valence than the $\mathrm{X}$ element exhibiting Slater-Pauling behavior $[12,13]$. In the last category, quaternary Heusler alloys have the form of XX'YZ and composed of different transition elements where the valence of $\mathrm{X}$ is higher than the valence of $\mathrm{X}$ ' which is higher than the valance of $\mathrm{Y}$.

Because of their remarkable properties, all four groups of Heusler alloys have been subjected to many diverse theoretical studies up to date [14-20]. However, although much efforts have been spent on different types of Heusler alloys [21-24], it is still necessary to clarify and understand the basic physical aspects of these alloys. Despite the $\mathrm{Rh}_{2} \mathrm{MnX}$ (X=Ti, Hf, Sc, Zr, Zn) novel magnetic Heusler alloys are first reported by Stefano et al. [25] in 2017, there are still only a few studies [26, 27-28] on these alloys. So, in this work, we focused on the electronic, elastic, mechanical, optical and magnetic properties of (X=Ti, Hf, Sc, Zr, Zn) Heusler alloys to contribute to the lacking literature of $\mathrm{Rh}_{2} \mathrm{MnHf}, \mathrm{Rh}_{2} \mathrm{MnSc}, \mathrm{Rh}_{2} \mathrm{MnSc}, \mathrm{Rh}_{2} \mathrm{MnzZr}$ and $\mathrm{Rh}_{2} \mathrm{MnZn} \mathrm{Heusler}$ alloys.

Hereafter, we present the computational details of this work in Section 2. As well, Section 3. of the paper imparts the result and discussion part in detail where Section 4. yields and summarizes the important findings of our work with conclusions. As far as we know, this is the first detailed theoretical work performed on the electronic, elastic, mechanical, optical and magnetic properties of $\mathrm{Rh}_{2} \mathrm{MnX}$ alloys. Therefore, this study may be useful for the scant experimental researches of these alloys in the next future.

\section{Computational Details}

We performed all calculations with the CASTEP code [29,30]. We employed generalized gradient approximation (GGA) [31] of density functional theory (DFT) within Perdew, Burke and Ernzerhof (PBE) exchangecorrelation energy [32] through spin-polarized calculations of the addressed alloys. We employed ultrasoft pseudo-potential scheme with $600 \mathrm{eV}$ cut-off energy for $\mathrm{Rh}_{2} \mathrm{MnX}$ alloys. We have used $11 \mathrm{x} 11 \mathrm{x} 11 \mathrm{Monkhorst-}$ Pack [33] k point sampling mesh considering the Broyden-Fletcher-Goldfarb-Shanno (BFGS) full geometry optimization algorithm [34-36]. The self-consistent convergence of total energy was fixed to a value of 5 x10-6 eV/atom. The maximum force was adjusted as $0.01 \mathrm{eV} / \AA$ where maximum displacement was kept to be as $5 \times 10^{-4} \AA$ under maximum stress with $0.02 \mathrm{GPa}$. The computed lattice parameters of the alloys were $6.16 \AA, 6.38 \AA, 6.33 \AA, 6.28 \AA$ and $6.05 \AA$ for $\mathrm{Rh}_{2} \mathrm{MnTi}, \mathrm{Rh}_{2} \mathrm{MnZr}, \mathrm{Rh}_{2} \mathrm{MnHf}, \mathrm{Rh}_{2} \mathrm{MnzSc}$ and Rh $\mathrm{MnZn}_{2}$, respectively. Fig. 1 shows the crystal structure of presently computed $\mathrm{Rh}_{2} \mathrm{MnTi}$ as a precursor of $\mathrm{Rh} \mathrm{M}_{2} \mathrm{MnX}$ alloys where Table 1. summarizes and compares the lattice constants of all calculated alloys. The crystal space group of the surveyed alloys are $F m$-3m under cubic symmetry with space group number 225 . In these alloys, Rh atoms occupy the $8 \mathrm{c}$ Wyckoff position $(1 / 4,1 / 4,1 / 4)$ and the $\mathrm{Mn}$ and $\mathrm{X}$ atoms are at the $4 \mathrm{a}$ $(0,0,0)$ and $4 \mathrm{~b}(1 / 2,1 / 2,1 / 2)$ positions, respectively. The resulting crystal exists with four interpenetrating face-centered cubic lattices, where the $\mathrm{Y}$ and $\mathrm{Z}$ atoms form an octahedral-coordinated rock-salt structure and the $\mathrm{X}$ atoms occupy the tetrahedral voids [25]. Similar to $\mathrm{Rh}_{2} \mathrm{MnTi}$ alloy, geometric conditions are also the same for the rest of other surveyed alloys of this study.

3. Results and Discussion

3.1 Elastic constants and related mechanical properties

As well-known in literature [38-41], cubic materials have three characteristic independent elastic constants 
i.e. $\mathrm{C}_{11}, \mathrm{C}_{12}$ and $\mathrm{C}_{44}$. From these constants, $\mathrm{C}_{11}$ defines the longitudinal elastic behavior of a given cubic material, whereas $\mathrm{C}_{12}$ represents the off-diagonal and $\mathrm{C}_{44}$ points out the shear elastic characteristic of related material. In our work, first principles density functional theory (DFT) implemented in the CASTEP code has been used to calculate the above three independent typical cubic elastic constants of $\mathrm{Rh}_{2} \mathrm{MnX}$ alloys. Table 2. lists $\mathrm{C}_{11}, \mathrm{C}_{12}$ and $\mathrm{C}_{44}$ values for $\mathrm{Rh}_{2} \mathrm{MnX}$ alloys. From Table 2 it is easy to verify the presence of traditional Born mechanical (dynamical) stability conditions with $\mathrm{C}_{11}>0, \mathrm{C}_{44}>0, \mathrm{C}_{11}-\mathrm{C}_{12}>0, \mathrm{C}_{11}$ $+\mathrm{C}_{12}>0$ and cubic stability i.e. $\mathrm{C}_{12}<?<\mathrm{C}_{12}$ where $(\mathrm{B})$ is the bulk modulus of regarding materials [38-41]. Noteworthy to mention here, bulk modulus defines the resistance amount of a given material under external deformations where the shear modulus $(\mathrm{G})$ describes materials resistance to the shape change under a shearing force. The Young's modulus (E) describes the resistance of the material to uniaxial tensions and represents the stiffness degree, i.e., the higher the value of $\mathrm{E}$, the stiffer is the material [42-47]. Table 2. also shows the calculated values of bulk modulus, shear modulus, Young's modulus of $\mathrm{Rh}_{2} \mathrm{MnX}$ alloys. In addition to these three important moduli $(\mathrm{B}, \mathrm{G}$ and $\mathrm{E})$, the $\mathrm{B} / \mathrm{G}$ ratio of any material identifies the brittle or ductile nature of the material. If the $\mathrm{B} / \mathrm{G}$ ratio of a material is more or less than the limiting value of 1.75 , then the material displays a ductile or brittle character [38-47]. It is also clear in Table 2. that the $\mathrm{B} / \mathrm{G}$ ratio of all alloys is bigger than the limiting value which means that all of them are ductile. Moreover, Poisson's ratio $(\nu)$ is the ratio between the transverse strain $\left(\mathrm{e}_{t}\right)$ and longitudinal strain $\left(\mathrm{e}_{l}\right)$ in the elastic loading direction. It provides detailed knowledge about the bonding character of solids. Usually, Poisson's ratio $\mathrm{s}$ ratio values are about 0.1 for covalent materials, 0.25 for ionic materials and vary between 0.28 and 0.42 for metals [47]. Poisson's ratio values of $\mathrm{Rh}_{2} \mathrm{MnX}$ alloys rise between 0.29 and 0.34 as in Table 2. So, it is apparent that all $\mathrm{Rh}_{2} \mathrm{MnX}$ alloys demonstrate metallic bonding. When compared with previous work of Ref. [26], although the metallic behavior of $\mathrm{Rh}_{2} \mathrm{MnTi}$ alloys correlates well with their findings, our elastic constants, elastic moduli and Vickers's hardness $\left(\mathrm{H}_{\mathrm{V}}=0.92(\mathrm{G} / \mathrm{B})^{1.37} \cdot \mathrm{G}^{0.708}\right)$ data somewhat underestimate their findings for this alloy (Table 2). Also, when we compare our results with former results of Refs. [27,28] our elastic and mechanical data slightly overestimate the results of Refs. [27,28] (Table 2). Therefore, we can ensure that the differences between the results of this work and Ref. [26] as well as Refs. [27,28] may mostly arise from the three distinct calculation methods.

\subsection{Electronic and Magnetic Properties}

The electronic band structure of any periodic crystal corresponds to energy eigenvalues and helps us to figure out the Fermi levels of the material which determine the conducting, semiconducting, or insulating aspect of any material. Fig.2 exemplifies the electronic band structure of $\mathrm{Rh}_{2} \mathrm{MnTi}$ alloy as a precursor for spin down (-) and spin up (-) states. The band structure of $\mathrm{Rh}_{2} \mathrm{MnTi}$ alloy in Fig. 2, display a clear metallic nature in which the valence and conduction bands intersect each other along with the chosen high symmetry points. The same result is also valid for the rest of other concerned alloys like $\mathrm{Rh}_{2} \mathrm{MnHf}, \mathrm{Rh}_{2} \mathrm{MnSc}$, $\mathrm{Rh}_{2} \mathrm{MnSc}, \mathrm{Rh}_{2} \mathrm{MnzZr}$ and $\mathrm{Rh}_{2} \mathrm{MnZn}$. Further, our analysis on the orbital-selective partial density of states of $\mathrm{Rh}_{2} \mathrm{MnTi}$ revealed that the conductivity of these alloys mainly originates from the large contributions of the d-electrons of $\mathrm{Rh}$ and $\mathrm{Mn}$ atoms as seen in Fig. 3. The same findings are also true again for other alloys having Hf, Sc, Zn and Zr. Since s, p orbitals do not much contribute to the conductivity of these alloys we did not provide any results for them. Also, to ensure this neglected effect of s and p orbitals we also give the element-specific partial density of states of $\mathrm{Rh}_{2} \mathrm{MnTi}$ alloy with the total contributions of alloying elements in Fig.4. Moreover, in Fig.3 and Fig.4, the density of states plots either for spin down or spin up components display a non-symmetrical picture due to a clear polarization between the density of states of these components. In particular, our results for electronic band structure and partial density of states of $\mathrm{Rh}_{2} \mathrm{MnTi}$ alloy are in good agreement with findings of Ref. [26]

Since $\mathrm{Rh}_{2} \mathrm{MnX}$ alloys are declared as potential novel magnetic alloys in its original theoretical work [25], we computed the magnetic moment $\left(\mu_{\mathrm{B}}\right)$ values of these alloys after spin-polarized calculations. Table 3. compares the calculated total magnetic moment $\left(\mu_{\mathrm{B}}\right)$ values of $\mathrm{Rh} 2 \mathrm{MnX}$ alloys with several former results. Our calculated values for the magnitudes of $\mu_{\mathrm{B}}$ are in the range of $\mathrm{Ti}>\mathrm{Zr}>\mathrm{Hf}>\mathrm{Sc}>\mathrm{Zn}$ and this result compare well with the findings of Refs. [25-27] with ferromagnetic ordering. 


\subsection{Optical properties}

For a detailed work of $\mathrm{Rh}_{2} \mathrm{MnX}$ alloys, we have also calculated the variation of the several optical properties versus the photon energy e.g. the dielectric function, optical conductivity, refractive index, loss function, absorption and reflectance. Present optical calculations were performed along with the [100] polarization under energies up to $30 \mathrm{eV}$.

Fig. 5 denotes complete optical properties of $\mathrm{Rh}_{2} \mathrm{MnTi}$ alloy where other optical spectra of remaining alloys are displayed together to make a benchmark between all computed alloys. The absorption spectrum of any material signifies the region at which the maximum photo excitation occurs [48,49]. As well, it provides useful data on the optimum solar energy conversion efficiency. The variation of absorption in Fig. 5 for $\mathrm{Rh}_{2} \mathrm{MnTi}$ and Fig.6 for other alloys exhibit identical absorption nature under incident energy. The absorption peaks of all computed alloys give two substantial maxima around $5 \mathrm{eV}$ and $25 \mathrm{eV}$ and imply slight or rapid falls after their last maximum.

Reflectivity offers the part of the incident energy of a wave reflected from the surface of any material $[48,49]$. The reflectivity peaks for $\mathrm{Rh}_{2} \mathrm{MnTi}$ in Fig. 5 and other alloys in Fig.7 show similarities again for their first maximum peaks at $5 \mathrm{eV}$. Further, under increasing energy, second maximums of the reflectivity peaks of $\mathrm{Rh}_{2} \mathrm{MnTi}, \mathrm{Rh}_{2} \mathrm{MnZr}$ and $\mathrm{Rh}_{2} \mathrm{MnSc}$ appear around $22.5 \mathrm{eV}$. Unlike them, second maximum reflectivity peaks of $\mathrm{Rh}_{2} \mathrm{MnHf}$ arise at $20 \mathrm{eV}$ and $\mathrm{Rh}_{2} \mathrm{MnZn}$ at $27.5 \mathrm{eV}$ in Fig.7. Hence, we can easily state that the reflectivity characteristics of studied alloys strongly depend on the alloying elements.

As being another key optical property, the complex dielectric function $\varepsilon(\omega)$ with the relation $\varepsilon(\omega)=\varepsilon_{\mathrm{r}}(\omega)+$ $\varepsilon_{i}(\omega)$ explains the optical properties of a medium under different photon energies where $\varepsilon r(\omega)$ stand for the real part $(\operatorname{Re})$ and $\varepsilon i(\omega)$ denotes the imaginary $(\operatorname{Im})$ part of the dielectric function $[48,49]$. Fig. 8 shows the Re and Im parts of the dielectric function of all studied alloys. Including the dielectric function of $\mathrm{Rh}_{2} \mathrm{MnTi}$ in Fig.5, real and imaginary parts of dielectric functions of $\mathrm{Rh}_{2} \mathrm{MnHf}$ and $\mathrm{Rh}_{2} \mathrm{MnZn}$ alloys begin with the negative values where the peak positions are different and have discrete height positions. In other words, real and imaginary parts of these alloys are smaller than zero under $2.5 \mathrm{eV}$. This specific result indicates the presence of metallic behavior. After the energy values bigger than $2.5 \mathrm{eV}$, they become positive and follow the unity for the entire energy range. On the other side, real and imaginary parts of the dielectric function of $\mathrm{Rh}_{2} \mathrm{MnSc}$ and $\mathrm{Rh}_{2} \mathrm{MnZr}$ alloys keep their positive character from beginning to end with different peak positions and track the unity under energy range up to $30 \mathrm{eV}$.

The optical conductivity of any material closely relates to dielectric function. It is also an effective tool to measure the electronic states of the material that proposes information about the optical excitations in a given material $[48,49]$. Fig. 9 represents the variation of real and imaginary parts of the optical conductivity with a change in the energy up to $30 \mathrm{eV}$ for studied alloys. In general, with different peak positions, all addressed alloys show analogous conductivity behavior where real and imaginary parts of the conductivity always appear in the positive region for all alloys.

Fig. 10 illustrates the refractive indexes ( $\mathrm{n}$ and $\mathrm{k}$ ) of considered alloys as a function of energy. Both the real part of the refractive index (n) and the imaginary part of the refractive index (also known as extinction coefficient (k)) located at different peak positions show diverse characteristics under energy. For example, $\mathrm{Rh}_{2} \mathrm{MnTi}$ (Fig.5) and $\mathrm{Rh}_{2} \mathrm{MnHf}$ alloys always preserve their positive tendency along with the whole energy range. Unlike, other alloys $\left(\mathrm{Rh}_{2} \mathrm{MnSc}, \mathrm{Rh}_{2} \mathrm{MnZn}\right.$ and $\left.\mathrm{Rh}_{2} \mathrm{MnZr}\right)$ experience a sluggish drop to zero for energies bigger than $20 \mathrm{eV}$ and subsequently follow the positive regime after this energy value.

The electron energy loss function is a noteworthy feature of materials associates with the energy loss of a moving electron in a material $[48,49]$. The existing peaks in the electron energy loss function symbolize the resonance frequency which is also recognized as plasma frequency. For any material, the material acts like a dielectric above resonance frequency and below this limit it behaves like a metal. Fig. 11. implies the variation of the electron energy loss function against photon energy for computed alloys. Except for the fluctuating loss function of $\mathrm{Rh}_{2} \mathrm{MnHf}$ alloy, all other alloys exhibit a clear and sharp peak after $20 \mathrm{eV}$. This energy region above $20 \mathrm{eV}$ also relates to the cooperative vibration of valance electrons and proves the 
plasma oscillations of $\mathrm{Rh}_{2} \mathrm{MnTi}$ (Fig.5), $\mathrm{Rh}_{2} \mathrm{MnSc}, \mathrm{Rh}_{2} \mathrm{MnZn}$ and $\mathrm{Rh}_{2} \mathrm{MnZr}$ alloys.

\section{Conclusions}

In this work, we addressed the electronic, elastic, mechanical, optical and magnetic properties of $\mathrm{Rh}_{2} \mathrm{MnX}$ (X=Ti, Hf, Sc, Zr, Zn) Heusler alloys by employing DFT with CASTEP code. From the attained results of this study, we can draw and summarize the following conclusions:

1. According to our obtained elastic data $\mathrm{Rh}_{2} \mathrm{MnX}$ (X=Ti, Hf, Sc, Zr, Zn) Heusler alloys are mechanically stable.

2. As another significant finding of our elastic constants data, $\mathrm{Rh}_{2} \mathrm{MnX}(\mathrm{X}=\mathrm{Ti}, \mathrm{Hf}, \mathrm{Sc}, \mathrm{Zr}, \mathrm{Zn})$ Heusler alloys show ductile mechanical character.

3. Vickers's hardness scale of the surveyed alloys follows the order of $\mathrm{Ti}>\mathrm{Sc}>\mathrm{Zr}>\mathrm{Hf}>\mathrm{Zn}$.

4. The analysis of Poisson's ratios of these alloys denotes that $\mathrm{Rh}_{2} \mathrm{MnX}(\mathrm{X}=\mathrm{Ti}, \mathrm{Hf}, \mathrm{Sc}, \mathrm{Zr}, \mathrm{Zn}$ ) Heusler alloys have metallic bonding.

5. The calculated spin up (-) and spin down (-) electronic bands are composed of intersecting valence and conduction bands which is another clear proof of the metallic behavior of $\mathrm{Rh}_{2} \mathrm{MnX}(\mathrm{X}=\mathrm{Ti}, \mathrm{Hf}$, $\mathrm{Sc}, \mathrm{Zr}, \mathrm{Zn}$ ) Heusler alloys. Electronic band structures also reveal the existing conductivity of $\mathrm{Rh}_{2} \mathrm{MnX}$ $(\mathrm{X}=\mathrm{Ti}, \mathrm{Hf}, \mathrm{Sc}, \mathrm{Zr}, \mathrm{Zn})$ Heusler alloys mostly emerges from the large d-electron contributions of these alloys.

6. Optical properties data also support and agree with the results of elastic and electronic band structure findings of $\mathrm{Rh}_{2} \mathrm{MnX}$ ( $\mathrm{X}=\mathrm{Ti}$, Hf, Sc, $\mathrm{Zr}, \mathrm{Zn}$ ) Heusler alloys with typical metallic conductivity and loss function peaks.

VII. All $\mathrm{Rh}_{2} \mathrm{MnX}$ alloys exhibit strong ferromagnetic ordering. follow Total magnetic moment $\left(\mu_{\mathrm{B}}\right)$ rank is $\mathrm{Ti}>\mathrm{Zr}>\mathrm{Hf}>\mathrm{Sc}>\mathrm{Zn}$ and vary from $\mu_{\mathrm{B}}=3.40$ to 4.82. Our results for $\mu_{\mathrm{B}}$ are also reasonable with prior theoretical data of Rh2MnX (X=Ti, Hf, Sc, Zr, Zn) Heusler alloys.

\section{References}

[1] W. Everhart, J. Newkirk, Heliyon 5 (2019) e01578.

[2] C. Felser, A. Hirohata, Eds., Heusler Alloys, Springer International Publishing, 2016.

[3] G. Rogl, S. Ghosh, L. Wang, J. Bursik, A. Grytsiv, M. Kerber, E. Bauer, R. C. Mallik, X.-Q. Chen, M. Zehetbauer, P. Rogl, Acta Materialia 2020, 183, 285.

[4] S. Idrissi, S. Ziti, H. Labrim, L. Bahmad, I. El Housni, R. Khalladi, S. Mtougui, N. El Mekkaoui, Journal of Alloys and Compounds 2020, 820, 153373.

[5] M. I. Khan, H. Arshad, M. Rizwan, S. S. A. Gillani, M. Zafar, S. Ahmed, M. Shakil, Journal of Alloys and Compounds 2020, 819, 152964.

[6] S. A. Khandy, J.-D. Chai, Journal of Applied Physics 2020, 127, 165102.

[7] L. Fan, F. Chen, C. Li, X. Hou, X. Zhu, J. Luo, Z.-Q. Chen, Journal of Magnetism and Magnetic Materials 2020, 497, 166060 .

[8] Y. Zhang, W. Zhang, X. Yu, C. Yu, Z. Liu, G. Wu, F. Meng, Materials Science and Engineering: B 2020, 260,114654 .

[9] G. Forozani, A. A. Mohammad Abadi, S. M. Baizaee, A. Gharaati, Journal of Alloys and Compounds $2020,815,152449$.

[10] M. Blinov, A. Aryal, S. Pandey, I. Dubenko, S. Talapatra, V. Prudnikov, E. Lähderanta, S. Stadler, V. Buchelnikov, V. Sokolovskiy, M. Zagrebin, A. Granovsky, N. Ali, Phys. Rev. B 2020, 101, 094423.

[11] C. Felser, L. Wollmann, S. Chadov, G.H. Fecher, S.S.P. Parkin, APL Materials 3 (2015) 041518.

[12] Z. Bai, L. Shen, G. Han, Y. P. Feng, SPIN 2012, 02, 1230006. 
[13] L. Wollmann, A. K. Nayak, S. S. P. Parkin, C. Felser, Annu. Rev. Mater. Res. 2017, 47, 247.

[14] S. A. Sofi, D. C. Gupta, J. Sol. Stat. Chem. 2020, 284, 121178.

[15] F. Meng, S. Liu, K. Sun, R. Gao, X. Shi, H. Luo, Journal of Magnetism and Magnetic Materials 2020, 514,167161 .

[16] R. Murugeswari, M. Manikandan, R. Rajeswarapalanichamy, A. Milton Franklin Benial, Int. J. Mod. Phys. B 2020, 34, 2050055.

[17] M. Ram, A. Saxena, N. Limbu, H. Joshi, A. Shankar, Journal of Applied Physics 2020, 128, 053901.

[18] S. R. Hari, V. Srinivas, C. R. Li, Y. K. Kuo, J. Phys.: Condens. Matter 2020, 32, 355706.

[19] Y. Gupta, M. M. Sinha, S. S. Verma, Physica B: Condensed Matter 2020, 590, 412222.

[20] S. Berri, J Supercond Nov Magn 2020, https://doi.org/10.1007/s10948-020-05638-4.

[21] D. M. Hoat, N. H. Giang, M. Naseri, R. Ponce-Pérez, J. F. Rivas-Silva, G. H. Cocoletzi, Physics Letters A $2020,384,126589$.

[22] H. Abbassa, A. Labdelli, S. Meskine, Y. B. Cherif, A. Boukortt, Mod. Phys. Lett. B 2019, 34, 2050028.

[23] D. J. Mokhtari, I. Jum'h, H. Baaziz, Z. Charifi, T. Ghellab, A. Telfah, R. Hergenröder, Philosophical Magazine 2020, 100, 1636.

[24] K. Belkacem, Y. Zaoui, S. Amari, L. Beldi, B. Bouhafs, SPIN 2020, 10, 2050022.

[25] S. Sanvito, C. Oses, J. Xue, A. Tiwari, M. Zic, T. Archer, P. Tozman, M. Venkatesan, M. Coey, S. Curtarolo, Sci. Adv. 3 (2017) e1602241.

[26] F. Benzoudji, D. Bensaid, A. el Kader Yakoubi, O. Arbouche, A.Z. Bouyakoub, N. Moulay, A. Mohammedi, M. Ameri, J Supercond Nov Magn 32 (2018) 1415-1421

[27] A. Jain, S.P. Ong, G. Hautier, W. Chen, W.D. Richards, S. Dacek, S. Cholia, D. Gunter, D. Skinner, G. Ceder, K.A. Persson, APL Materials 1 (2013) 011002.

[28] M. de Jong, W. Chen, T. Angsten, A. Jain, R. Notestine, A. Gamst, M. Sluiter, C. Krishna Ande, S. van der Zwaag, J.J. Plata, C. Toher, S. Curtarolo, G. Ceder, K.A. Persson, M. Asta, Sci Data 2 (2015).

[29] S. J. Clark, M. D. Segall, C. J. Pickard, P. J. Hasnip, M. I. J. Probert, K. Refson, M. C. Payne, Zeitschrift für Kristallographie - Crystalline Materials 2005, 220, DOI 10.1524/zkri.220.5.567.65075.

[30] M. D. Segall, P. J. D. Lindan, M. J. Probert, C. J. Pickard, P. J. Hasnip, S. J. Clark, M. C. Payne, J. Phys.: Condens. Matter 2002, 14, 2717

[31] J.P. Perdew, J.A. Chevary, S.H. Vosko, K.A. Jackson, M.R. Pederson, D.J. Singh, C. Fiolhais, Phys. Rev. B 46 (1992) 6671-6687.

[32] J.P. Perdew, K. Burke and M. Ernzerhof, Phys. Rev. Lett. 78 (1997) 1396.

[33] H.J. Monkhorst and J.D. Pack, Phys. Rev. B 13 (1976) 5188.

[34] C. G. Broyden, IMA J Appl Math 1970, 6, 76.

[35] R. Fletcher, The Computer Journal 1970, 13, 317.

[36] D. Goldfarb, Math. Comp. 1970, 24, 23.

[37] D. F. Shanno, Math. Comp. 1970, 24, 647.

[38] M. Güler, E. Güler, Mater. Res. Express 2016, 3, 075901.

[39] E. Güler and M. Güler, Chin. J. Phys. 2015, 52(5) 1625. 
[40] E. Güler, M. Güler, Braz J Phys 2015, 45, 296.

[41] E. Güler, M. Güler, Mat. Res. 2014, 17, 1268.

[42] M. Güler, E. Güler, Chinese Phys. Lett. 2013, 30, 056201.

[43] M. Güler, E. Güler, Braz J Phys 2016, 46, 192.

[44] M. Güler and E. Güler, Crystals 2017, 7, 164.

[45] E. Güler, M. Güler, Int. J. Mod. Phys. B 2015, 29, 1550222.

[46] E. Güler, M. Güler, J. Optoelectron. Adv. Mater 2014, 16, 1222.

[47] E. Güler, M. Güler, Appl. Phys. A 2015, 119, 721.

[48] A.K. Kushwaha, Ş. Uğur, M. Güler, E. Güler, G. Uğur

Physica B: Condensed Matter 596 (2020) 412404.

[49] G. Uğur, A.K. Kushwaha, M. Güler, Z. Charifi, Ş. Uğur, E. Güler, H. Baaziz, Materials Science in Semiconductor Processing (2020) 105531.

\section{FIGURE CAPTIONS}

Figure 1. Crystal structure ofRh ${ }_{2} \mathrm{MnTi}$ alloy. Crystal geometry is also the same for other $\mathrm{Rh}_{2} \mathrm{MnX}$ alloys.

Figure 2: Electronic band structure of minority (-) and majority spins (-) of $\mathrm{Rh}_{2} \mathrm{MnTi}$ alloy.

Figure 3. Orbital-selective partial density of states of $\mathrm{Rh}_{2} \mathrm{MnTi}$ alloy with d-orbitals of alloying elements.

Figure 4. Element-specific partial density of states of $\mathrm{Rh}_{2} \mathrm{MnTi}$ alloy with total contributions of alloying elements.

Figure 5. All optical properties of $\mathrm{Rh}_{2} \mathrm{MnTi}$ alloy.

Figure 6. Absorption peaks for $R h_{2} M n H f, R h_{2} M n z S c, ~ R h_{2} M n Z n$ and $R h_{2} M n Z r$ alloys versus to energy.

Figure 7. Reflectivity plots of $R_{2} \mathrm{MnHf}, \mathrm{Rh}_{2} \mathrm{MnzSc}, \mathrm{Rh}_{2} \mathrm{MnZn}$ and $\mathrm{Rh}_{2} \mathrm{MnZr}$ alloys.

Figure 8. Dielectric function of $R_{2} \mathrm{MnHf}, \mathrm{Rh}_{2} \mathrm{MnzSc}, \mathrm{Rh}_{2} \mathrm{MnZn}$ and $R \mathrm{~h}_{2} \mathrm{MnZr}$ alloys.

Figure 9. The conductivity of $R h_{2} M n H f, R h_{2} M n z S c, R h_{2} M n Z n$ and $R h_{2} M n Z r$ alloys.

Figure 10. Refractive indexes ofRh $h_{2} \mathrm{MnHf}, \mathrm{Rh}_{2} \mathrm{MnzSc}, \mathrm{Rh}_{2} \mathrm{MnZn}$ and $R \mathrm{~h}_{2} \mathrm{MnZr}$ alloys.

Figure 11. Loss function of $R_{2} \mathrm{MnHf}, \mathrm{Rh}_{2} \mathrm{MnzSc}, \mathrm{Rh}_{2} \mathrm{MnZn}$ and $R \mathrm{~h}_{2} \mathrm{MnZr}$ alloys. 


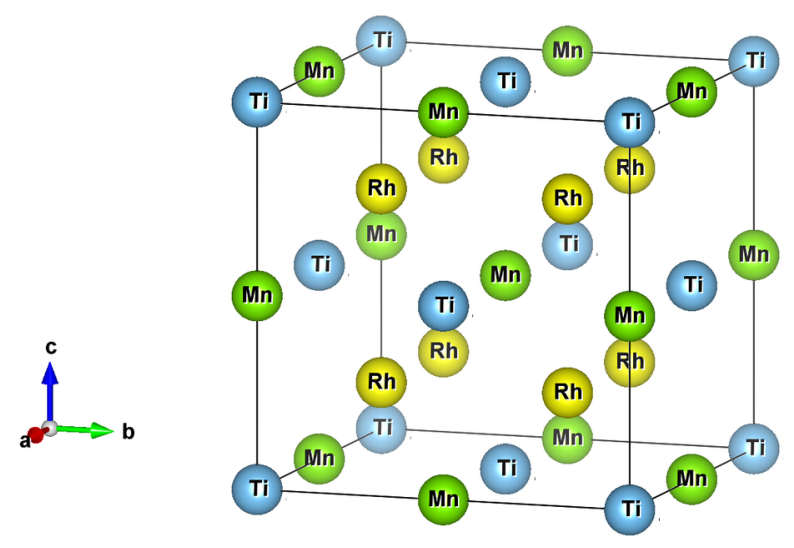

Fig. 1
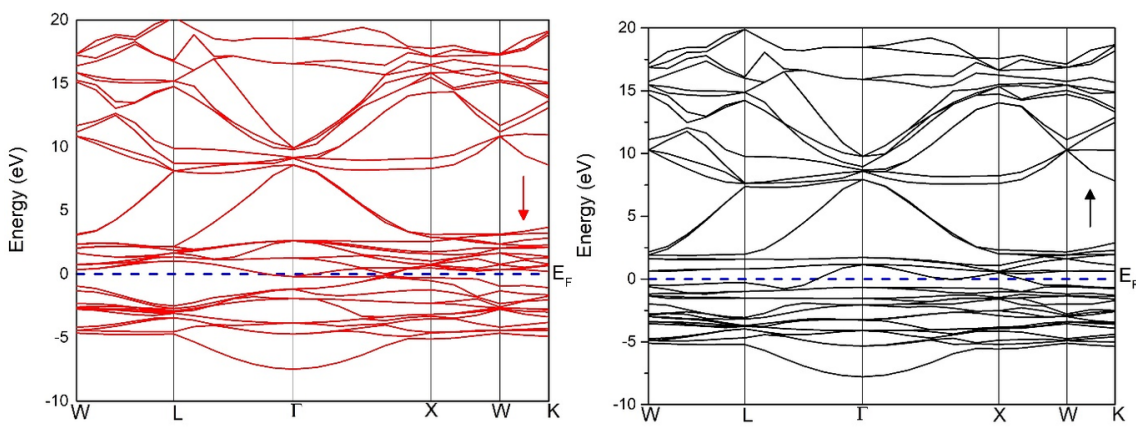

Fig. 2

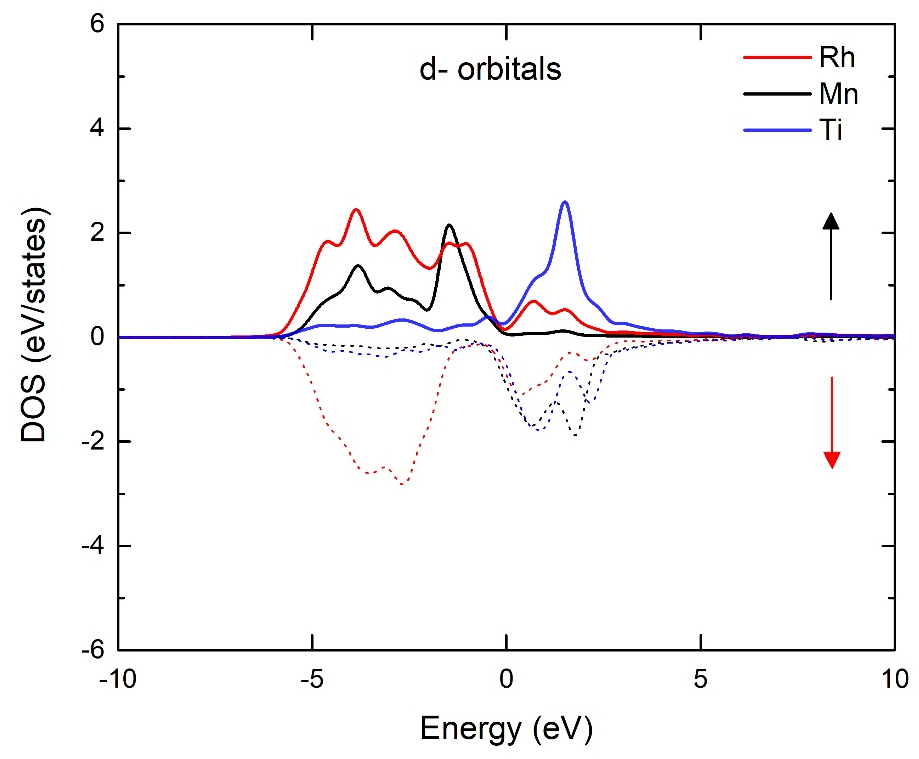


Fig. 3

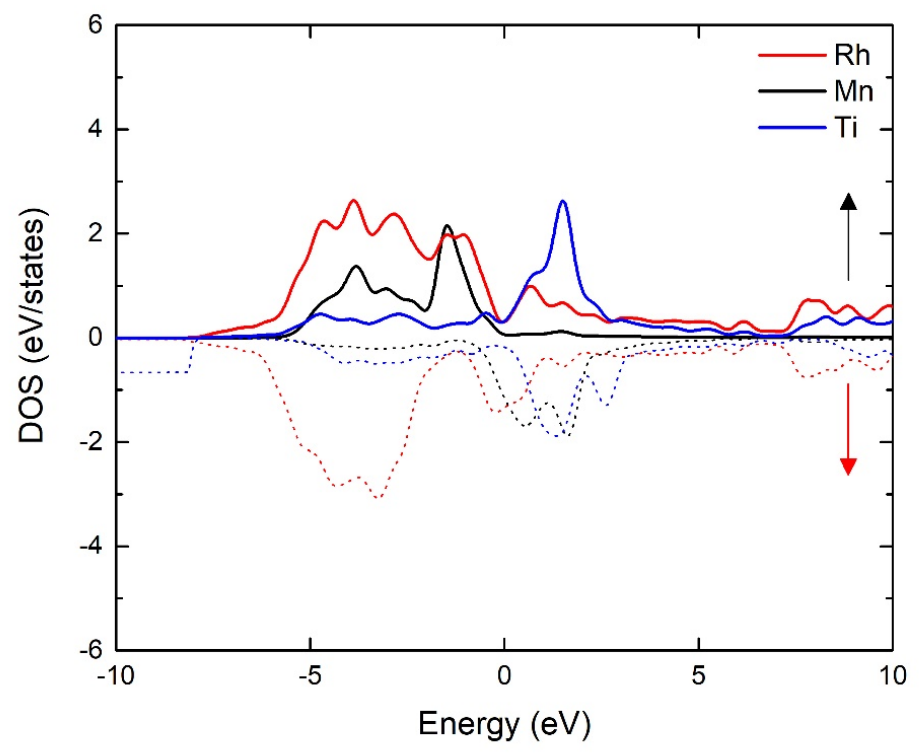

Fig. 4 

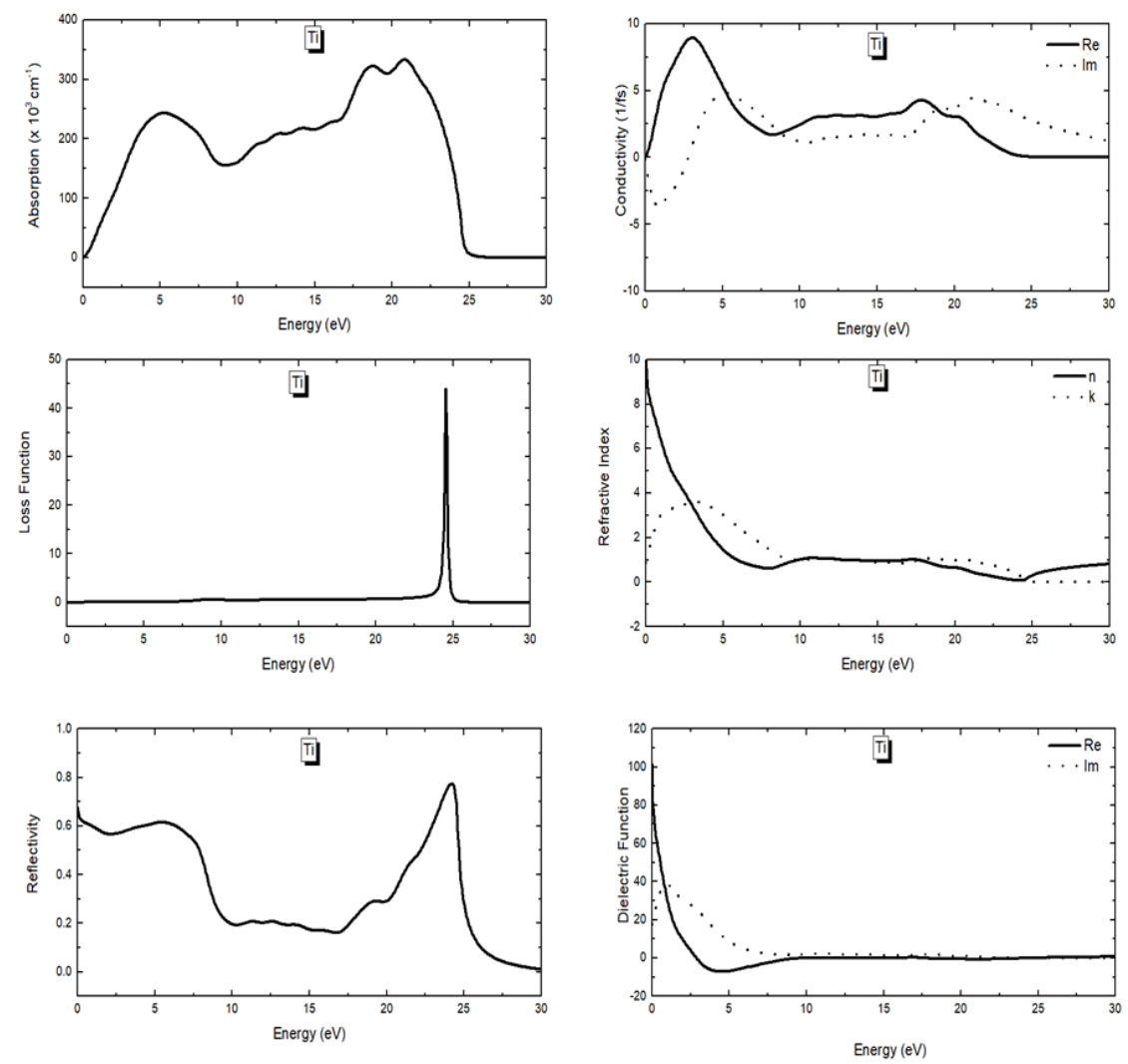

Fig. 5 


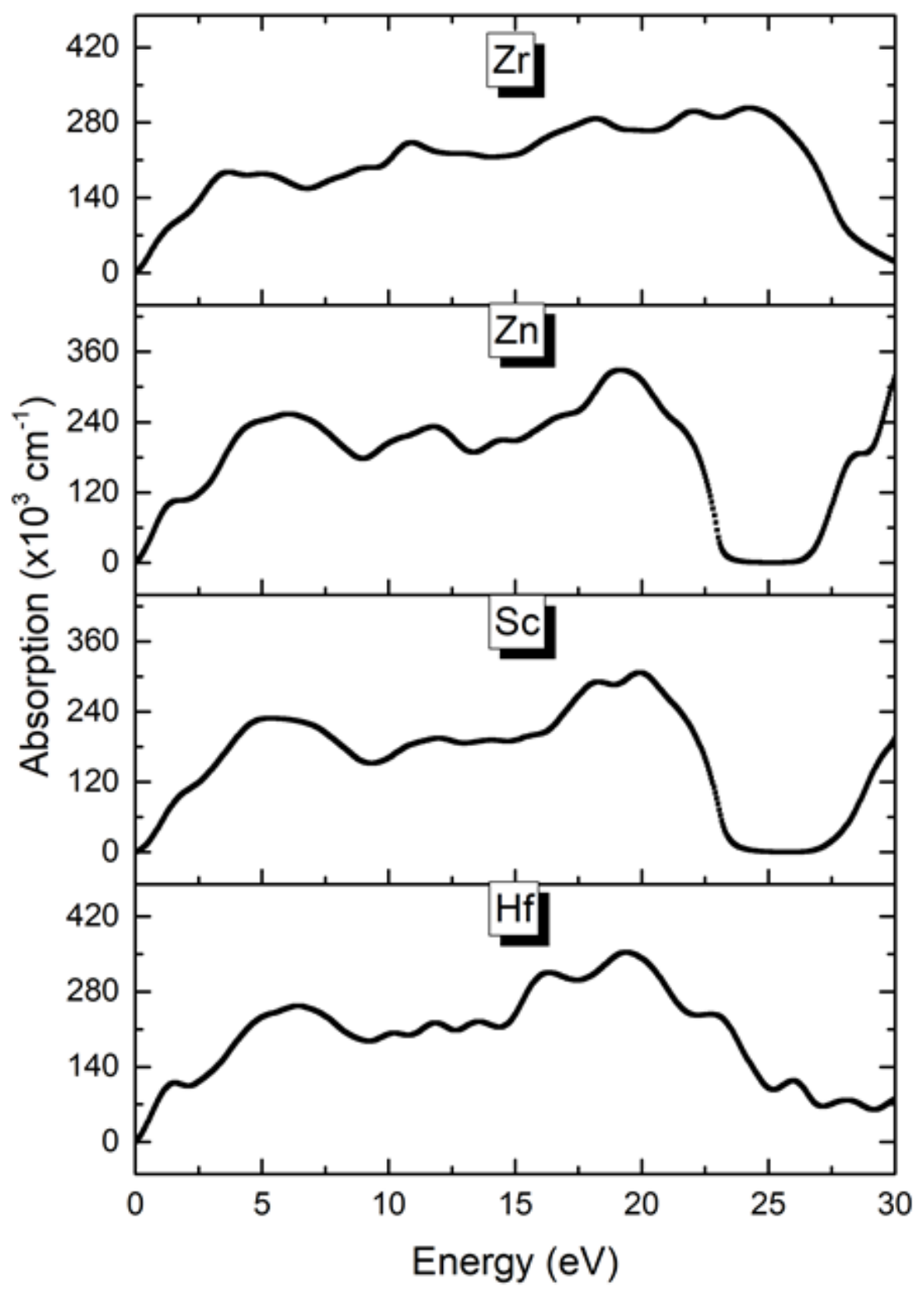

Fig. 6 


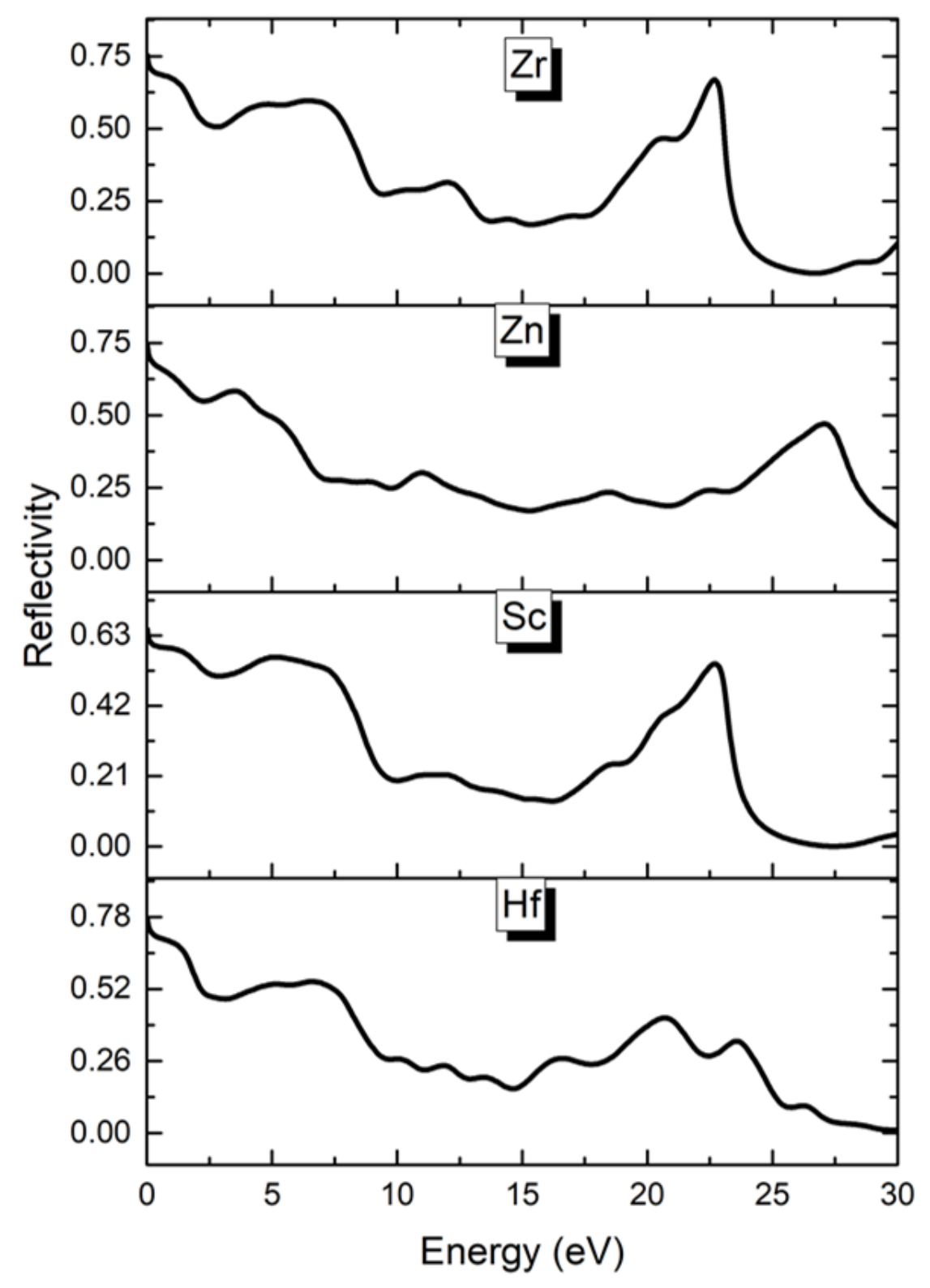

Fig. 7 

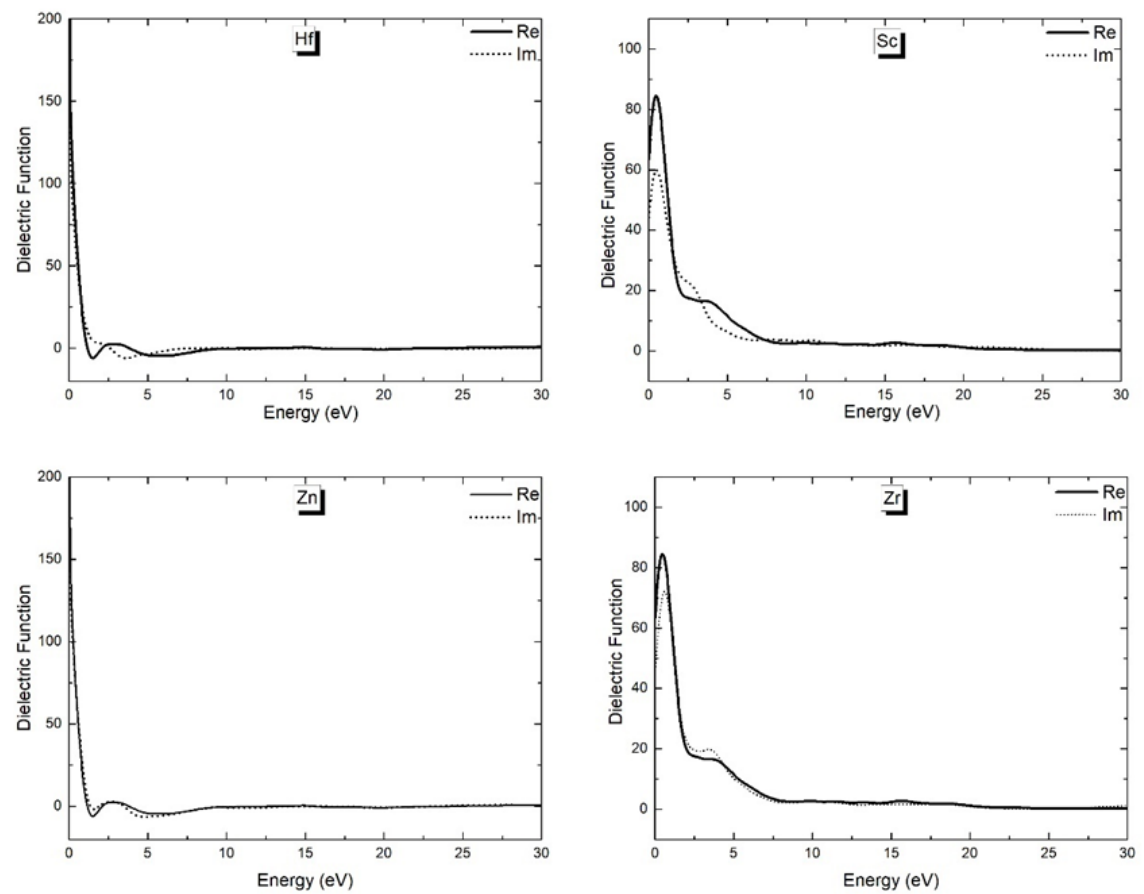

Fig. 8

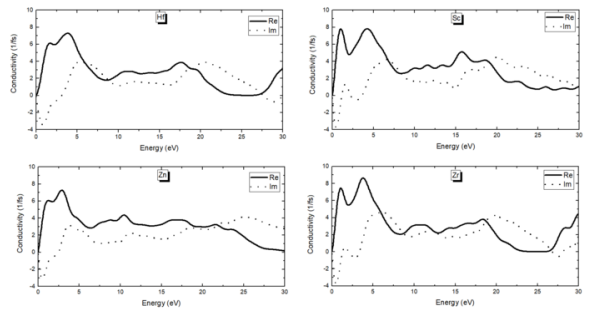

Fig. 9 

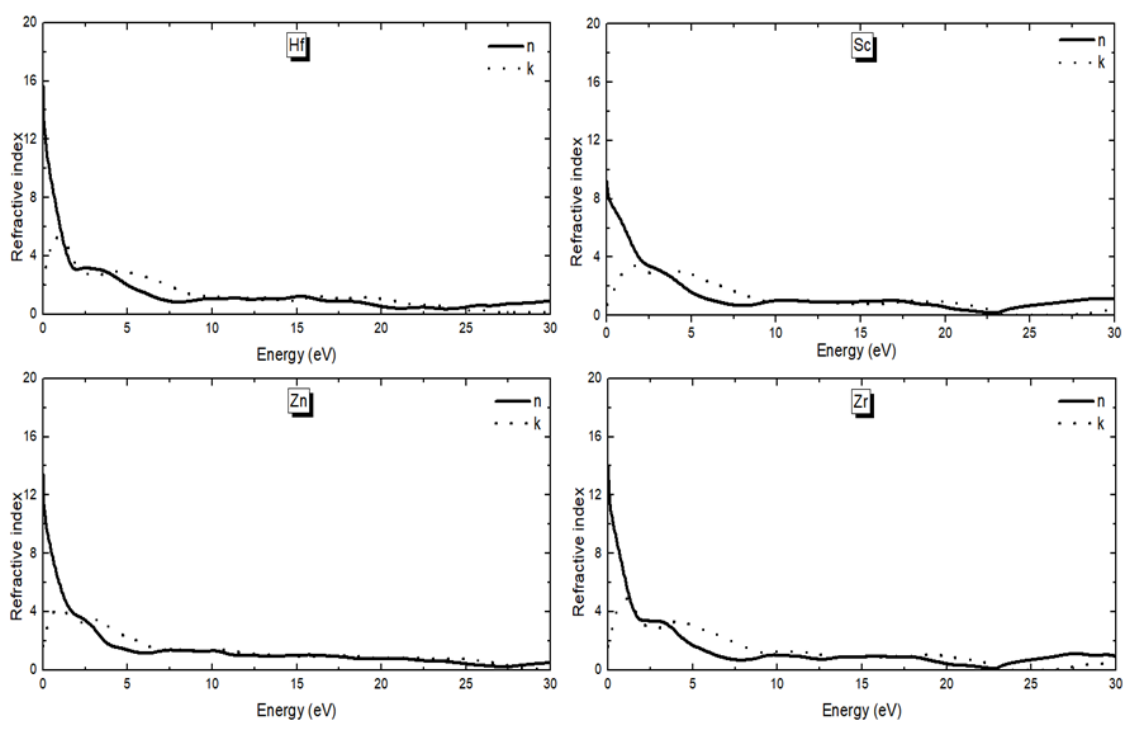

Fig. 10 


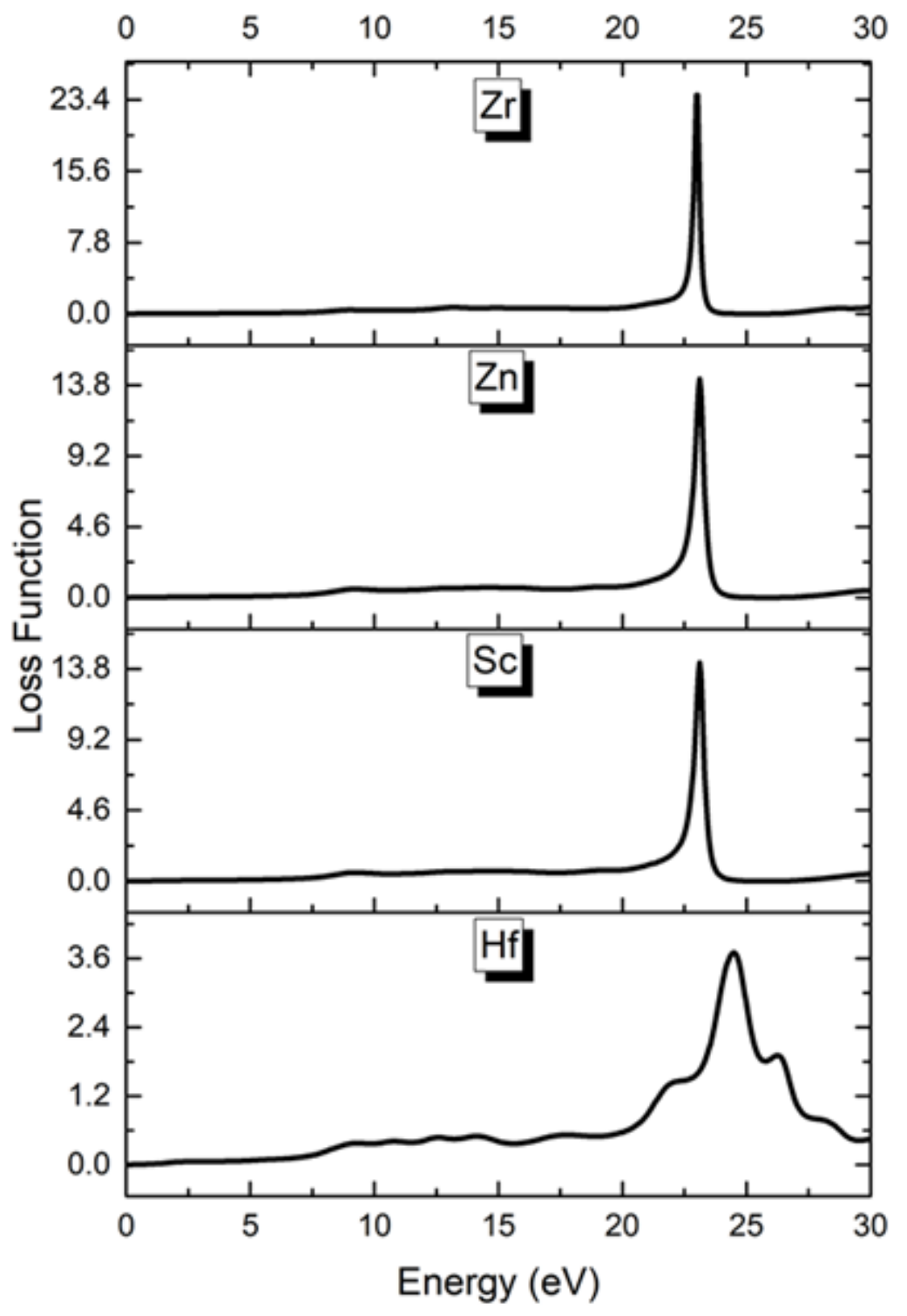

Fig. 11

\section{TABLE CAPTIONS}

Table 1. Lattice parameters of presently calculated $\mathrm{Rh}_{2} \mathrm{MnX}$ alloys.

\begin{tabular}{lllll}
\hline Alloy & (This work) & {$[25]$} & {$[26]$} & {$[27]$} \\
\hline $\mathrm{Rh}_{2} \operatorname{MnX}$ & $\mathrm{a}_{0}(\AA)$ & $\mathrm{a}_{0}(\AA)$ & $\mathrm{a}_{0}(\AA)$ & $\mathrm{a}_{0}(\AA)$ \\
$\mathrm{Ti}$ & 6.16 & 6.15 & 6.13 & 6.16 \\
$\mathrm{Zr}$ & 6.38 & 6.37 & - & 6.38 \\
$\mathrm{Hf}$ & 6.33 & 6.32 & - & 6.33
\end{tabular}




\begin{tabular}{lllll}
\hline Alloy & (This work) & {$[25]$} & {$[26]$} & {$[27]$} \\
\hline $\mathrm{Sc}$ & 6.28 & 6.27 & - & 6.28 \\
$\mathrm{Zn}$ & 6.05 & 6.03 & - & 6.05 \\
\hline
\end{tabular}

\begin{tabular}{|c|c|c|c|c|c|c|c|c|}
\hline $\mathrm{Rh}_{2} \mathrm{Mn} \mathrm{X}$ & $\mathrm{C}_{11}(\mathrm{GPa})$ & $\mathrm{C}_{12}(\mathrm{GPa})$ & $\mathrm{C}_{44}(\mathrm{GPa})$ & $\mathrm{B}(\mathrm{GPa})$ & $\mathrm{G}(\mathrm{GPa})$ & $\mathrm{E}(\mathrm{GPa})$ & $\mathrm{B} / \mathrm{G}$ & $\nu$ \\
\hline $\begin{array}{l}\mathrm{Ti} \\
\text { (This } \\
\text { work) }\end{array}$ & 267.2 & 134.7 & 102.9 & 178.9 & 86.2 & 222.9 & 2.07 & 0.29 \\
\hline $\mathrm{Ti}[26]$ & 350.2 & 146.6 & 198.9 & 214.5 & 152.0 & 368.9 & 1.41 & 0.213 \\
\hline $\mathrm{Ti}[28]$ & 248.0 & 151.0 & 93.0 & 183.0 & 72.0 & 191.5 & 2.54 & 0.33 \\
\hline $\begin{array}{l}\text { Hf } \\
\text { (This } \\
\text { work) }\end{array}$ & 243.2 & 127.7 & 92.8 & 166.2 & 76.7 & 199.5 & 2.17 & 0.299 \\
\hline Hf [28] & 239.0 & 146.0 & 89.0 & 177.0 & 68.0 & 180.8 & 2.60 & 0.33 \\
\hline $\begin{array}{l}\text { Sc } \\
\text { (This } \\
\text { work) }\end{array}$ & 214.3 & 102.6 & 67.3 & 139.9 & 62.4 & 163.1 & 2.23 & 0.305 \\
\hline $\mathrm{Sc}[28]$ & 221.0 & 116.0 & 69.0 & 151.0 & 62.0 & 163.6 & 2.43 & 0.32 \\
\hline $\begin{array}{l}\text { Zr } \\
\text { (This } \\
\text { work) }\end{array}$ & 206.0 & 118.5 & 82.3 & 147.7 & 63.9 & 167.5 & 2.31 & 0.31 \\
\hline $\begin{array}{l}\text { Zn } \\
\text { (This } \\
\text { work) }\end{array}$ & 187.8 & 141.4 & 114.9 & 156.8 & 61.3 & 162.8 & 2.55 & 0.32 \\
\hline Zn [28] & 199.0 & 153.0 & 112.0 & 168.0 & 60.0 & 160.8 & 2.80 & 0.34 \\
\hline
\end{tabular}

Table 2. Some elastic and related mechanical parameters of $R h_{2} M n X$ alloys.

Table 3. Presently calculated total magnetic moments of Rh2MnX alloys.

\begin{tabular}{lllll}
\hline Alloy & This work & {$[25]$} & {$[26]$} & {$[27]$} \\
\hline $\mathrm{Rh}_{2} \mathrm{MnX}$ & $\mu_{\mathrm{B}}$ & $\mu_{\mathrm{B}}$ & $\mu_{\mathrm{B}}$ & $\mu_{\mathrm{B}}$ \\
$\mathrm{Ti}$ & 4.82 & 4.80 & 4.80 & 4.81 \\
$\mathrm{Zr}$ & 4.77 & 4.75 & - & 4.79 \\
$\mathrm{Hf}$ & 4.74 & 4.74 & - & 4.78 \\
$\mathrm{Sc}$ & 4.40 & 4.31 & - & 0.038 \\
$\mathrm{Zn}$ & 3.40 & 3.37 & - & 3.24 \\
\hline
\end{tabular}

